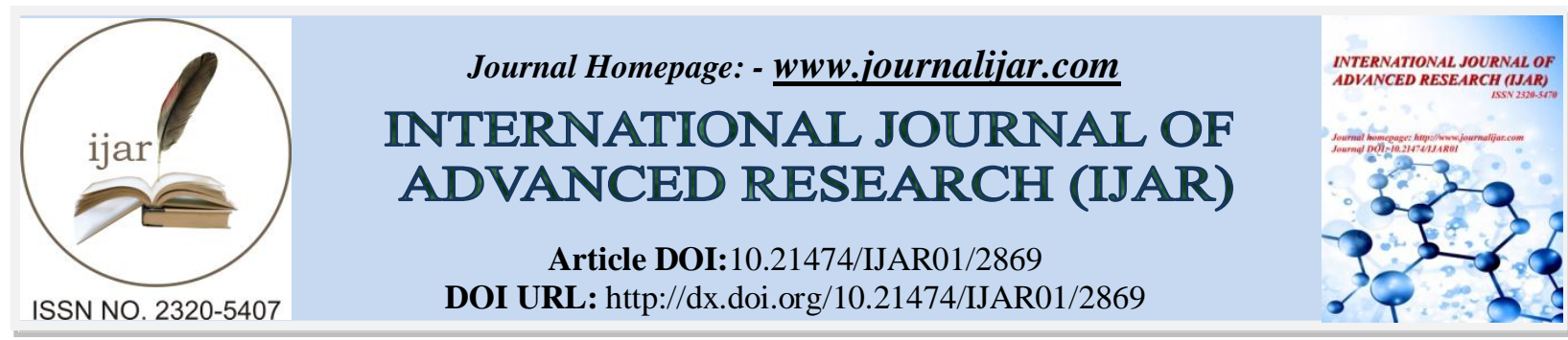

RESEARCH ARTICLE

\title{
CELL SUSPENSION CULTURE - AN IMPROVED SYSTEM FOR PRODUCTION OF COLCHICINE FROM GLORIOSA SUPERBA L.
}

\author{
G. S. Nikhila ${ }^{1}$, G. Sangeetha ${ }^{1}$, M. Devi Chinmayee ${ }^{1}$, T. S. Preetha ${ }^{1}$ and T. S. Swapna ${ }^{2} *$. \\ 1. Department of Botany, University College, Thiruvananthapuram-34, Kerala. \\ 2. Department of Botany, University of Kerala, Kariavattom, Thiruvananthapuram.
}

\section{Manuscript Info}

..........................

Manuscript History

Received: 21 November 2016

Final Accepted: 21 December 2016

Published: January 2017

Key words:-

Colchicine, Suspension cultures, HPLC, HPTLC, TLC.

\section{Abstract}

The present study focused on the identification, isolation and quantification of a major bioactive compound colchicine from the suspension culture of Gloriosa superba L. The plant is an ornamental climbing herb with tuberous roots and having numerous medicinal properties. Suspension culture was established in MS medium with different hormonal combinations. Phytochemicals were analysed from callus which later compared to the methanol extract from root tubers of Gloriosa superba.The presence of high amount of colchicine in the methanol extract of root tuberand the callus was confirmed through the HPLC. Both the tuber extractand callus indicated the presence of colchicine but the callus has only less amount of colchicine. So production of colchicine was enhanced through elicitation in the suspension cultures. Suspension culture of Gloriosa superba was established and production of colchicine was enhanced using various biotic and abiotic elicitors. Colchicine in the suspension culture was identified, quantified and isolated using various chromatographic techniques. The result showed that maximum colchicine production was induced by the biotic elicitor namely chitosan and colchicine was separated and quantified through HPLC, column chromatography, HPTLC, and TLC. The present study thus confirmed that the suspension culture of Gloriosa superba possessed high amount of colchicine and which has to be used for further investigation and evaluation of medicinal properties.

Copy Right, IJAR, 2016,. All rights reserved.

\section{Introduction:-}

Medicinal plants have played an important role in the development of human culture. Majority of the modern medicines are produced indirectly from medicinal plants and some plants are directly used as medicines. Many commonly used food crops also showed medicinal properties along with their nutritional qualities. Medicinal plants are the major resource for new drugs or drug leads, so the study of these plants helps to understand the pharmacological and therapeutic output and thereby give way for their sustainable utilization. The cultivation and preservation of medicinal plants also helps to protect the biological diversity (Irchhaiya et al., 2014).

The medicinal plant Gloriosa superbaL. is one of the perennial climbing herb belongs to the family Liliaceae. This plant has numerous medicinal properties and is used for curing major ailments like ulcers, piles, cancer, asthma, 
haemorrhoids, inflammation, malaria, leprosy and stomach aches. All parts of Gloriosa superba showed medicinal values. The leaf sap is used as a smoothening agent for skin eruptions. The V-shaped tuber is used for the treatment of cancer, haemorrhoids, chronic ulcers and also for inducing labour pains and also reported to have hepatoprotective (Nikhila et al., 2016) as well as anti-inflammatory activities (Nikhila et al., 2015). Root tuber with sesamum oil will reduce the pain in arthritis affected joints. Seeds are used for curing rheumatic pain and also act as muscle relaxant (Ravindra and Mahendra, 2009). The medicinal properties of the plant give evidence to the presence of major secondary metabolites. One of the major compound identified from Gloriosa superba is colchicine (Kavina et al., 2011). The cell suspension culture is an important technique for the production of secondary metabolites from the medicinal plants. Thus the main objective of the present study was focused on the isolation and quantification of a major compound colchicine from the suspension culture of Gloriosa superba through various chromatographic techniques.

\section{Materials and Methods:- \\ Establishment of Suspension Culture:-}

The callus was established using various explants like internode, leaves etc. inoculated with $\mathrm{M}$ S medium at different hormonal combinations. Then the six week old callus was transferred into liquid MS media. The cell suspension culture was grown for 25 days in the shaker and this culture was used for the production of secondary metabolites. For the enhancement of secondary metabolite production various types of elicitors were used periodically. The major elicitors used were chitosan, pectin, salicylic acid and calcium chloride at various concentration and incubated for 24, 48 and 72 hours (Gopi and Vatsala, 2006). Major bioactive compounds were identified and quantified using chromatographic techniques.

\section{Chromatographic Techniques:-}

For the identification, isolation and quantification of bioactive compounds various types of chromatographic techniques were used. In case of HPLC the retention time of sample was compared with that of the standard for the identification of colchicine. A C18 column with silica gel and acetonitrile: methanol: water (32:48:20) were used as the stationary phase and the mobile phase respectively.

Column chromatography is a method used to purify individual chemical compounds from mixtures of compounds. The Silica gel was used as the stationary phase and the mobile phase consisted of toluene: ethyl acetate: formic acid: methanol. The fractions obtained were subjected to High Pressure Thin Layer Chromatography. In HPTLC the silica gel used as stationary phase and toluene: ethyl acetate: formic acid: methanol was used as mobile phase. For TLC silica gel and the mixture hexane: chloroform used as stationary and mobile phase respectively (Asha et al., 2013).

\section{Results and Discussion:- \\ Suspension Culture:-}

The HPLC profiling showed that the crude methanol extract possessed high amount of colchicine compared to the other standards. Since it is present in high amount, the colchicine is selected as a major compound for further study. For the establishment of suspension culture $96 \%$ of the callusing was observed in the hormone combination NAA+ BAP at the concentration of $0.15+0.25 \mathrm{mg} / 1$. But the callus produces only lesser amount of colchicine [(Fig 1(a) and Fig 1(b)]. So the suspension culture which is ideal for production of colchicine was established and elicitors were used for enhanced production. The six week old callus were used for the elicitation of major compound namely colchicine (Fig: 2).

Suspension culture with the elicitor salicylic acid induced the production of $4.09 \mathrm{mg} / \mathrm{g}$ alkaloid within 48 hours at the concentration of $0.25 \mu \mathrm{M}$. The medium also have $1.86 \mathrm{mg} / \mathrm{g}$ alkaloid which exuded into the medium with in the 24 hours at the concentration of $5 \mu \mathrm{M}$ (Table 1). With the presence of $\mathrm{CaCl}_{2}$ maximum alkaloid production was observed at $0.5 \mu \mathrm{M}$ concentration within the 48 hours and $1.57 \mathrm{mg}$ alkaloid was exuded out into the medium at the concentration of $2.5 \mu \mathrm{M}$ within the 72 hours (Table 2). The Table 3 showed the effect of chitosan on alkaloid production. Maximum alkaloid production $(5.96 \mathrm{mg} / \mathrm{g})$ was noticed at the concentration of $1 \mathrm{mg}$ of chitosan. The medium also have $3.46 \mathrm{mg} / \mathrm{g}$ alkaloid at the concentration of $1 \mathrm{mgof}$ chitosan within the 48 hours. The Table 4 showed that $4.56 \mathrm{mg} / \mathrm{g}$ of alkaloid was produced at the concentration of $1 \mathrm{mg}$ of pectin and the medium also have $2.86 \mathrm{mg} / \mathrm{g}$ of alkaloid which was exuded out into the medium within the 48 hours. Pandurangan and Philomina, (2010) reported enhancement of colchicine by the addition of sulphate ions whereas in the present study addition of the chitosan enhanced the maximum production of colchicine in cell suspension culture of Gloriosa superba. 
HPTLC: The estimation and quantification of isolated compound from suspension culture was analysed by HPTLC. The result showed that the chitosan induces maximum amount of colchicine production in the suspension culture (Fig: 3)

\section{Column Chromatography:-}

The column chromatography of suspension culture provide 82 fractions. These fractions are subjected to the alkaloid test. Out of 82 fractions only 12 to 19 fractions showed positive result for the alkaloid test. Isolated fractions with alkaloid were subjected to HPTLC and also subjected to TLC using standard (Fig: 4). The spot with alkaloid was scratched out from the preparative TLC was used for further analysis which clarifies it as colchicine. These results were comparable with the previous work done by Kavina et al., (2011) where identification and quantification of colchicine from seed and tuber through various chromatographic techniques were reported.

\section{Conclusion:-}

It can be concluded that the suspension cultures of Gloriosa superba can suggested as an improved system for in vitro production the medicinally active compound colchicine. The present study will be helpful for the maximum utilization of the plant along with the identification and isolation of useful bioactive molecules.

Table 1:-Effect of salicylic acid on alkaloid production.

\begin{tabular}{|l|l|l|l|l|}
\hline Name of elicitor & Treatment duration & Conc.of elicitor & $\begin{array}{l}\text { Alkaloid in mg/g } \\
\text { (callus) }\end{array}$ & $\begin{array}{l}\text { Alkaloid in mg/g } \\
\text { (medium) }\end{array}$ \\
\hline Salicylic acid & $24 \mathrm{hr}$ & Control & $1.01 \pm 0.03$ & $0.59 \pm 0.06$ \\
& & $0.25 \mu \mathrm{M}$ & $1.32 \pm 0.05$ & $0.98 \pm 0.60$ \\
& $0.5 \mu \mathrm{M}$ & $1.23 \pm 0.08$ & $0.96 \pm 0.53$ \\
& $2.5 \mu \mathrm{M}$ & $1.09 \pm 0.12$ & $1.07 \pm 0.39$ \\
& & $5 \mu \mathrm{M}$ & $1.45 \pm 0.09$ & $1.86 \pm 0.05$ \\
\cline { 2 - 5 } & $48 \mathrm{hr}$ & $1.39 \pm 0.53$ & $0.63 \pm 0.88$ \\
& & $0.25 \mu \mathrm{M}$ & $4.09 \pm 0.59$ & $1.01 \pm 0.55$ \\
& $0.5 \mu \mathrm{M}$ & $3.67 \pm 0.07$ & $1.23 \pm 0.02$ \\
& $2.5 \mu \mathrm{M}$ & $2.87 \pm 0.64$ & $1.34 \pm 0.08$ \\
& $5 \mu \mathrm{M}$ & $3.65 \pm 0.34$ & $1.29 \pm 0.10$ \\
\cline { 2 - 5 } & $72 \mathrm{hr}$ & Control & $1.25 \pm 0.81$ & $0.69 \pm 0.41$ \\
& & $0.25 \mu \mathrm{M}$ & $2.43 \pm 0.45$ & $1.05 \pm 0.64$ \\
& $0.5 \mu \mathrm{M}$ & $3.56 \pm 0.53$ & $1.25 \pm 0.06$ \\
& $2.5 \mu \mathrm{M}$ & $2.33 \pm 0.23$ & $1.35 \pm 0.62$ \\
& & $5 \mu \mathrm{M}$ & $3.02 \pm 0.39$ & $1.26 \pm 0.07$ \\
\hline
\end{tabular}

Table 2:-Effect of calcium chloride on alkaloid production.

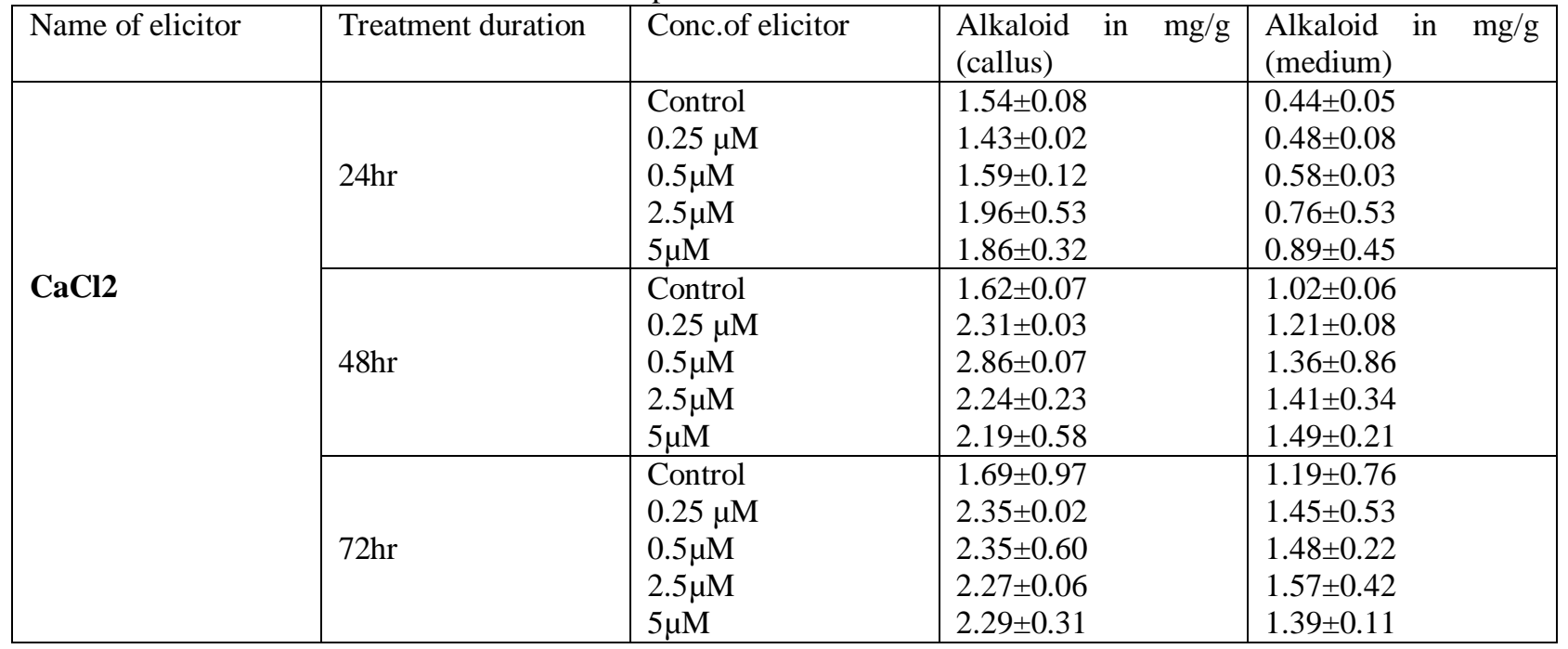


Table 3:-Effect of Chitosan on alkaloid production

\begin{tabular}{|c|c|c|c|c|}
\hline Name of elicitor & Treatment duration & Conc.of elicitor & 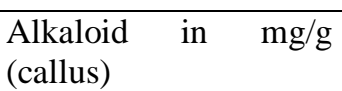 & $\begin{array}{l}\text { Alkaloid in } \mathrm{mg} / \mathrm{g} \\
\text { (medium) }\end{array}$ \\
\hline \multirow{3}{*}{ Chitosan } & $24 \mathrm{hr}$ & $\begin{array}{l}\text { Control } \\
0.5 \mathrm{mg} \\
1 \mathrm{mg} \\
1.5 \mathrm{mg} \\
2 \mathrm{mg}\end{array}$ & $\begin{array}{l}1.52 \pm 0.03 \\
2.33 \pm 0.08 \\
3.09 \pm 0.12 \\
2.86 \pm 0.32 \\
2.96 \pm 0.09\end{array}$ & $\begin{array}{l}1.04 \pm 0.21 \\
1.23 \pm 0.42 \\
1.49 \pm 0.15 \\
1.56 \pm 0.33 \\
1.66 \pm 0.61\end{array}$ \\
\hline & $48 \mathrm{hr}$ & $\begin{array}{l}\text { Control } \\
0.5 \mathrm{mg} \\
1 \mathrm{mg} \\
1.5 \mathrm{mg} \\
2 \mathrm{mg} \\
\end{array}$ & $\begin{array}{l}1.64 \pm 0.11 \\
3.41 \pm 0.02 \\
5.96 \pm 0.33 \\
4.34 \pm 0.51 \\
3.89 \pm 0.37 \\
\end{array}$ & $\begin{array}{l}1.52 \pm 0.44 \\
2.55 \pm 0.31 \\
3.46 \pm 0.08 \\
2.34 \pm 0.03 \\
2.49 \pm 0.01 \\
\end{array}$ \\
\hline & $72 \mathrm{hr}$ & $\begin{array}{l}\text { Control } \\
0.5 \mathrm{mg} \\
1 \mathrm{mg} \\
1.5 \mathrm{mg} \\
2 \mathrm{mg}\end{array}$ & $\begin{array}{l}1.79 \pm 0.04 \\
3.55 \pm 0.01 \\
4.45 \pm 0.06 \\
3.17 \pm 0.08 \\
3.65 \pm 0.04\end{array}$ & $\begin{array}{l}1.04 \pm 0.01 \\
1.23 \pm 0.24 \\
1.49 \pm 0.05 \\
1.56 \pm 0.52 \\
1.66 \pm 0.03\end{array}$ \\
\hline
\end{tabular}

Table 4:-Effect of Pectin on alkaloid production

\begin{tabular}{|c|c|c|c|c|}
\hline Name of elicitor & Treatment duration & Conc.of elicitor & $\begin{array}{l}\begin{array}{l}\text { Alkaloid } \\
\text { (callus) }\end{array} \\
\text { (n) } \mathrm{mg} / \mathrm{g}\end{array}$ & $\begin{array}{l}\begin{array}{l}\text { Alkaloid in } \\
\text { (medium) }\end{array}\end{array}$ \\
\hline \multirow{3}{*}{ Pectin } & $24 \mathrm{hr}$ & $\begin{array}{l}\text { Control } \\
0.5 \mathrm{mg} \\
1 \mathrm{mg} \\
1.5 \mathrm{mg} \\
2 \mathrm{mg} \\
\end{array}$ & $\begin{array}{l}1.22 \pm 0.01 \\
1.43 \pm 0.03 \\
2.59 \pm 0.12 \\
2.46 \pm 0.24 \\
2.66 \pm 0.21\end{array}$ & $\begin{array}{l}1.12 \pm 0.03 \\
0.98 \pm 0.21 \\
1.09 \pm 0.26 \\
1.16 \pm 0.07 \\
1.26 \pm 0.01\end{array}$ \\
\hline & $48 \mathrm{hr}$ & $\begin{array}{l}\text { Control } \\
0.5 \mathrm{mg} \\
1 \mathrm{mg} \\
1.5 \mathrm{mg} \\
2 \mathrm{mg}\end{array}$ & $\begin{array}{l}1.24 \pm 0.33 \\
2.11 \pm 0.43 \\
4.56 \pm 0.18 \\
3.04 \pm 0.22 \\
2.83 \pm 0.18\end{array}$ & $\begin{array}{l}1.26 \pm 0.21 \\
0.91 \pm 0.32 \\
2.86 \pm 0.08 \\
2.24 \pm 0.02 \\
2.07 \pm 0.04\end{array}$ \\
\hline & $72 \mathrm{hr}$ & $\begin{array}{l}\text { Control } \\
0.5 \mathrm{mg} \\
1 \mathrm{mg} \\
1.5 \mathrm{mg} \\
2 \mathrm{mg} \\
\end{array}$ & $\begin{array}{l}1.49 \pm 0.37 \\
3.01 \pm 0.03 \\
2.95 \pm 0.90 \\
3.07 \pm 0.55 \\
3.25 \pm 0.01\end{array}$ & $\begin{array}{l}1.24 \pm 0.15 \\
2.00 \pm 0.28 \\
2.35 \pm 0.17 \\
2.15 \pm 0.32 \\
2.25 \pm 0.39\end{array}$ \\
\hline
\end{tabular}

Fig 1:- (a) HPLC analysis of colchicine in the methanol tuber extract

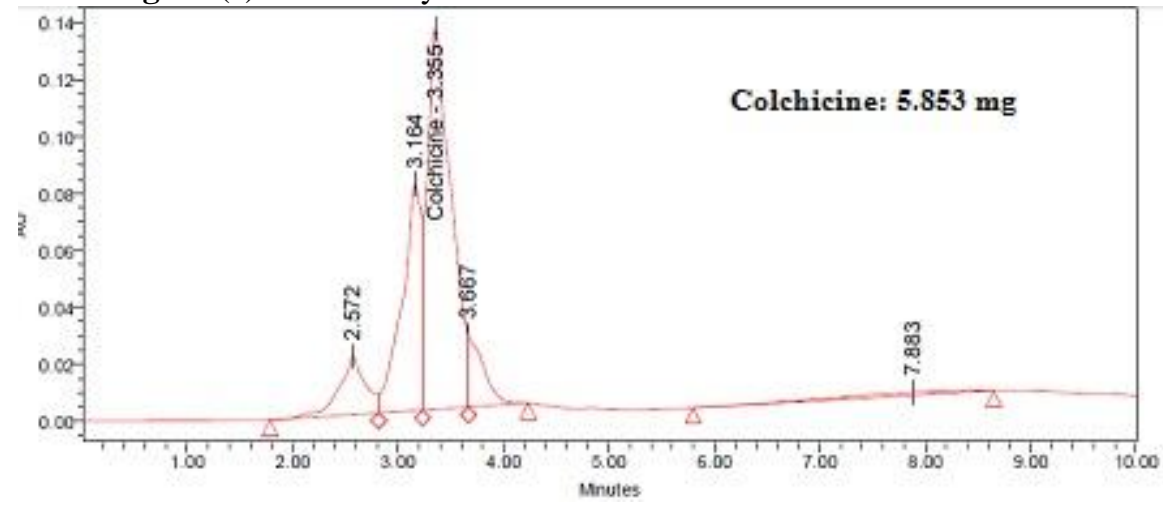


Fig 1:- (b) HPLC analysis of colchicine in the callus

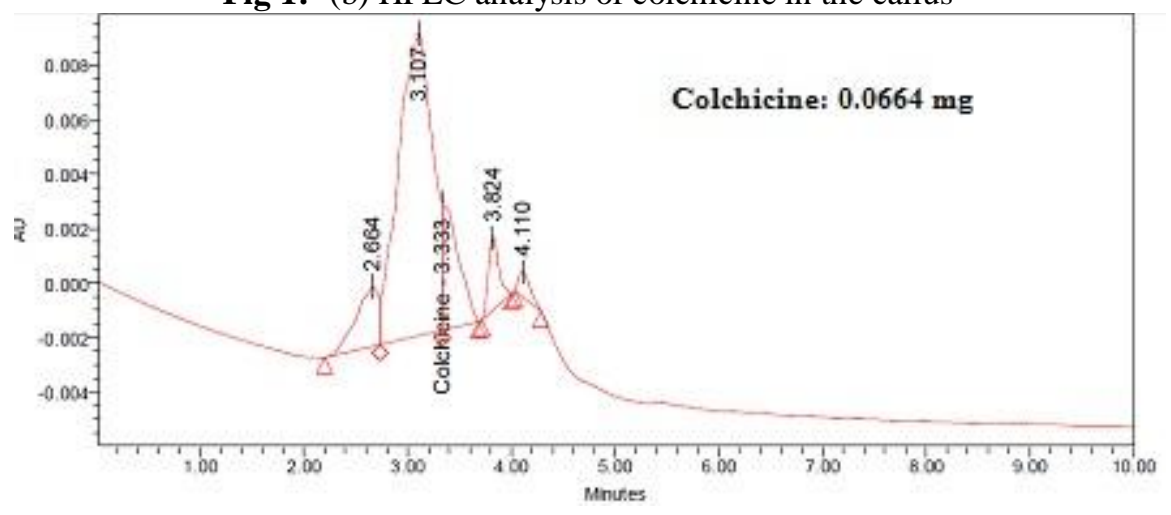

Fig 2:-Elicitation of Colchicine in Suspension culture

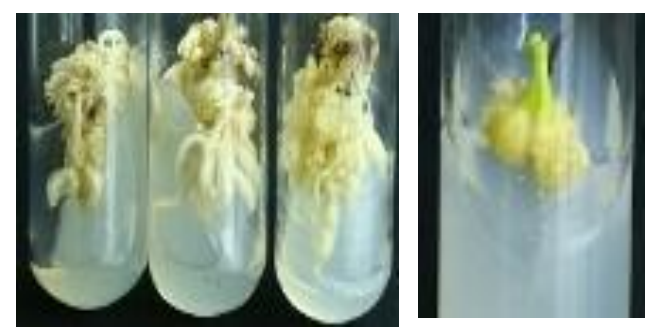

Four weeks old callus

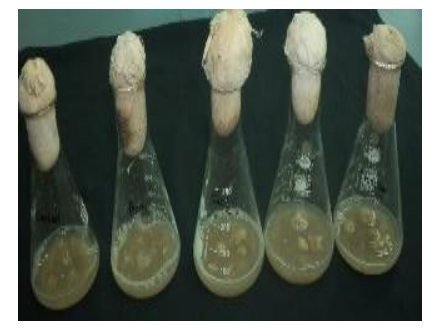

48 hrs culture

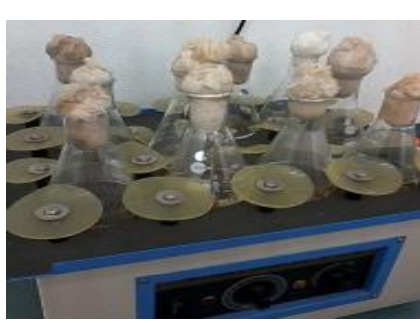

Elicitation process

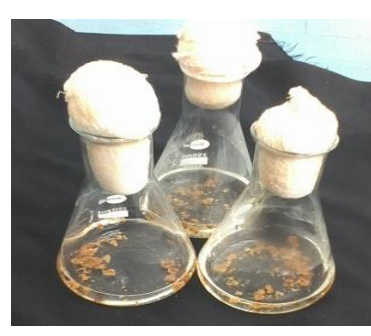

24 hrs culture

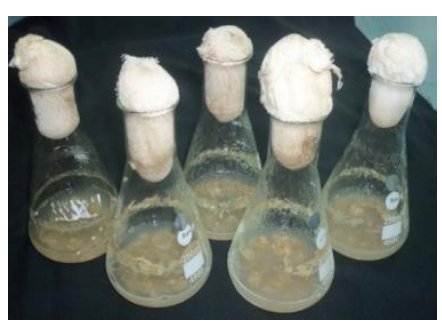

72 hrs culture 
Fig 3:-Estimation of Colchicine by HPTLC
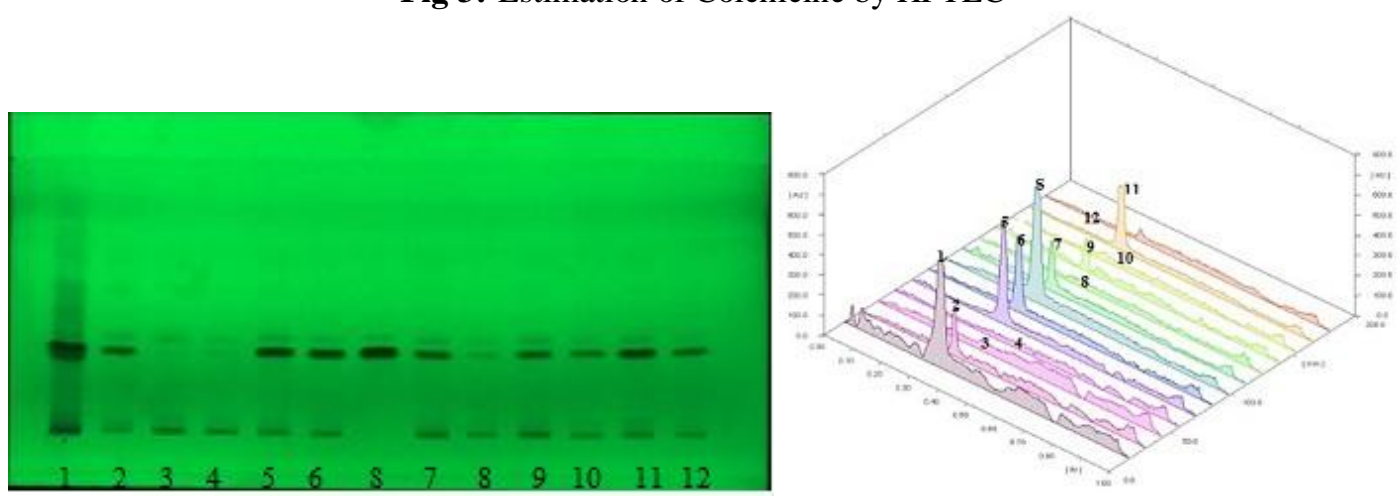

1. Tuber crude methanol, 2. Callus crude methanol, 3. Control callus, 4. Control medium, 5. Chitosan callus, 6. Chitosan medium, S. Standard, 7.SA callus, 8.Salicylic acid medium, 9. $\mathrm{Cacl}_{2}$ callus, 10. $\mathrm{Cacl}_{2}$ medium, 11. Pectin callus, 12. Pectin medium

Fig 4:-HPTLC of isolated fractions.

$366 \mathrm{~nm}$

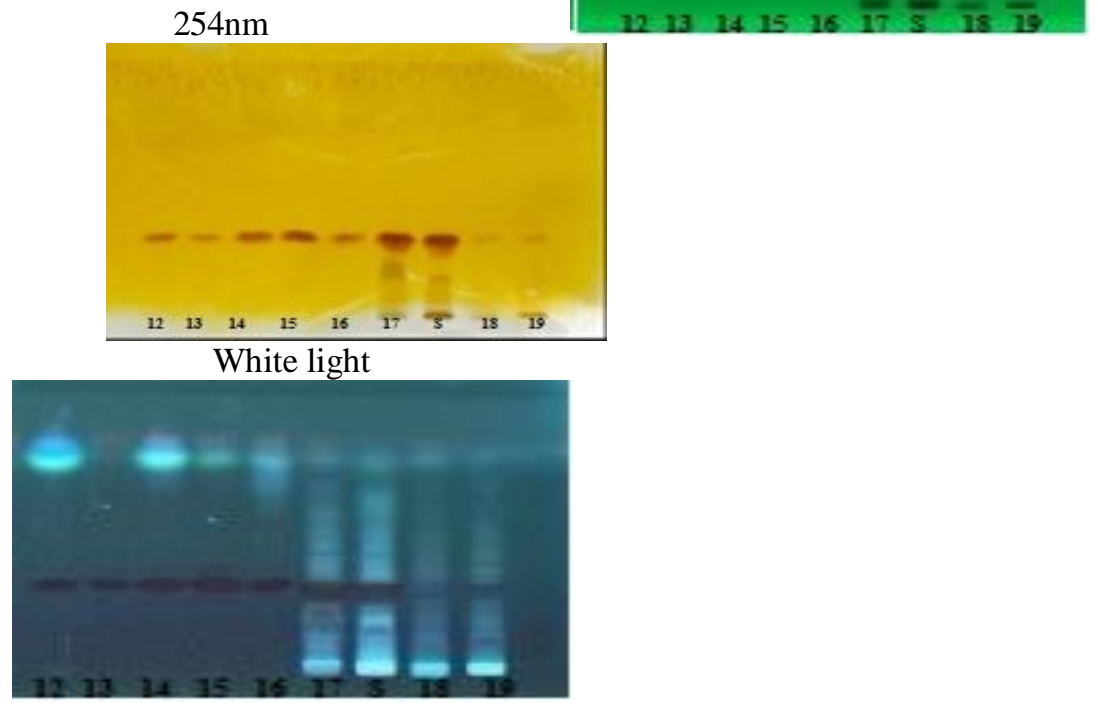




\section{Reference:-}

1. Asha, V., Namrata, S. and Arvind, K. (2013): Phytochemical investigation and thin layer chromatography of Asparagus racemosus methanolic leaves extract. International journal of Advaned Research in Pharmaceuticals and Bioscience., 3(1):15-18.

2. Gopi, C. and Vatsala, T.M. (2006): In vitro studies on effects of plant growth regulators on callus and suspension culture biomass yield from Gymnema sylvestre R. Br. Afr. J. Biotechnol., 5: 1215-1219.

3. Irchhaiya, R., Anurag, K., yadav, A., Gupta, N., Kumar, S., Gupta, N., Kumar, S., Yadav, V., Prakash, A. and Gurjar, H. (2014): Metabolites in plants and its classification. World journal of pharmacy and pharmaceutical sciences., 4 (1): 287-305.

4. Kavina, J., Gopi, R. and Paneerseivam, R. (2011): Quantification of Colchicine in Seed and Tuber samples of Gloriosa superba by High Performance Liquid Chromatography method. Journal of applied pharmaceutical science., 1(7):11-119.

5. Nikhila, G .S, Sangeetha, G. and Swapna T.S. (2015): Anti inflammatory properties of root tubers of Gloriosa superba and its conservation through micropropagation, Journal of Medicinal Plants Research, Vol 9(1): 1-7

6. Nikhila, G. S., Sangeetha, G., Devi Chinmayee, M. and Swapna, T. S. (2016): An investigation on phytochemical screening and hepatoprotective activity in an important medicinal herb Gloriosa superba L., International Journal of Applied and Pure Science and Agriculture, Volume 02, Issue 05: 133-137.

7. Pandurangan, B. and Philomina, D. (2010): Effect of nutritional factors and precursors on formation of colchicine in Gloriosa superba in vitro. Research in Biotechnology., 1:29-37.

8. Ravindra, A. and Mahendra, K.R. (2009): Review: Current advances in Gloriosa superba L. Biodiversitas., 10(4): 210-214. 